\title{
Natalizumab treatment reduces microglial activation in the white matter of the MS brain
}

Marcus Sucksdorff, MD, Jouni Tuisku, MSc, Markus Matilainen, PhD, Anna Vuorimaa, BM, Sarah Smith, BSc, Joonas Keitilä, BM, Johanna Rokka, MSc, PhD, Riitta Parkkola, MD, PhD, Marjo Nylund, MSc,

Juha Rinne, MD, PhD, Eero Rissanen, MD, PhD, and Laura Airas, MD, PhD

Neurol Neuroimmunol Neuroinflamm 2019;6:e574. doi:10.1212/NXI.0000000000000574

\section{Abstract}

\section{Objective}

To evaluate whether natalizumab treatment reduces microglial activation in MS.

\section{Methods}

We measured microglial activation using the $18-\mathrm{kDa}$ translocator protein (TSPO)-binding radioligand $\left[{ }^{11} \mathrm{C}\right]$ PK11195 and PET imaging in 10 patients with MS before and after 1 year treatment with natalizumab. Microglial activation was evaluated as the distribution volume ratio (DVR) of the specifically bound radioligand in brain white and gray matter regions of interest. MRI and disability measurements were performed for comparison. Evaluation was performed identically with 11 age- and sex-matched patients with MS who had no MS therapy.

\section{Results}

Natalizumab treatment reduced microglial activation in the normal-appearing white matter (NAWM; baseline DVR vs DVR after 1 year of treatment 1.25 vs $1.22, p=0.014$, Wilcoxon) and at the rim of chronic lesions (baseline DVR vs DVR after 1 year of treatment 1.24 vs $1.18, p$ $=0.014)$. In patients with MS with no treatment, there was an increase in microglial activation at the rim of chronic lesions ( 1.23 vs $1.27, p=0.045)$. No alteration was observed in microglial activation in gray matter areas. In the untreated patient group, higher microglial activation at baseline was associated with more rapid disability progression during an average of 4 years of follow-up.

\section{Conclusions}

TSPO-PET imaging can be used as a tool to assess longitudinal changes in microglial activation in the NAWM and in the perilesional areas in the MS brain in vivo. Natalizumab treatment reduces the diffuse compartmentalized CNS inflammation related to brain resident innate immune cells.

\author{
Correspondence \\ Dr. Sucksdorff \\ marsuc@utu.fi
}




\section{Glossary}

3D = 3 dimensional; 9 9HPT = 9-Hole Peg Test $\mathbf{B P}_{\mathbf{N D}}=$ binding potential; $\mathbf{D V R}=$ distribution volume ratio $; \mathbf{E D S S}=$ Expanded Disability Status Scale; $\mathbf{G M}=$ gray matter; $\mathbf{I Q R}=$ interquartile range; $\mathbf{N A W M}=$ normal-appearing white matter; $\mathbf{R O I}=$ region of interest; RRMS = relapsing-remitting MS; SPMS = secondary progressive MS; TSPO = translocator protein.

Neuropathologic studies have demonstrated microglial activation in the normal-appearing white matter (NAWM) and at the rim of chronic active/smoldering lesions in brains of patients with MS. ${ }^{1}$ The more advanced the disease, the more microglial activation has been seen. ${ }^{1}$ This observation has been confirmed in in vivo PET studies of patients with MS using $18-\mathrm{kDa}$ translocator protein (TSPO)-binding radioligands targeting activated microglia. ${ }^{2-6}$ In these crosssectional studies, TSPO binding in the NAWM or at the chronic active lesion rim has been significantly stronger among patients with secondary progressive MS (SPMS) compared with patients with relapsing-remitting MS (RRMS) or healthy controls. ${ }^{2-6}$

Transformation of relapsing MS into SPMS is clinically insidious and is known to be pathologically associated with CNS-resident innate immune cell activation. ${ }^{7}$ Microglia and macrophages have protective and homeostatic functions, such as clearing of debris. In acute MS lesions, they uptake the degraded myelin, which promotes remyelination. ${ }^{8}$ In progressive MS, microglia may instead acquire a harmful proinflammatory phenotype and promote neurotoxicity by secreting proinflammatory cytokines and free oxygen radicals. ${ }^{9}$ This may be one of the mechanisms driving chronic tissue damage in areas surrounding chronic active/smoldering lesions, and this is believed to be one of the mechanisms contributing to clinical disease progression. ${ }^{8}$ It is presently unknown whether blocking inflammatory activity with effective disease-modifying therapy alters microglia toward a less activated phenotype at sites related to progressive MS pathology. In this work, we addressed this question by performing an in vivo TSPO-PET imaging study in which we measured microglial activation longitudinally at 1 -year interval in patients with MS with or without natalizumab treatment.

\section{Methods}

\section{Study subjects}

The study subjects were initially recruited as part of an investigator-initiated substudy to the ASCEND study at the Turku University Hospital, Finland. ${ }^{10}$ ASCEND evaluated the effect of natalizumab on disease progression in SPMS. ${ }^{10}$ Because of the low number $(n=4)$ of study subjects participating in ASCEND at our center, patients with MS were also recruited for PET imaging from the Turku neurology outpatient clinic. The ASCEND patients were treated and followed up in a blinded fashion. The rest of the patients were evaluated clinically in an open-label fashion, with the image analyses performed in a blinded fashion. The final composition of the study cohort of 21 patients with MS is shown in the table, top section. Exclusion criteria included corticosteroid treatment within 30 days of evaluation, active neurologic or autoimmune disease other than MS or another comorbidity considered significant, inability to tolerate PET or MRI, and a current or desired pregnancy following study enrollment. None of the patients were JCV-Ab positive. TSPO-PET results from 8 similarly imaged age- and sex-matched healthy controls were used for comparison.

\section{Procedures}

Ten patients were imaged using PET and MRI at baseline before initiation of natalizumab treatment and 1 year later. Eleven patients without any disease-modifying treatment were imaged for comparison using the same protocol. Expanded Disability Status Scale (EDSS) evaluation and recording of relapses were performed at baseline and after 1 year (table, middle section). Safety monitoring was performed regularly at 1-month intervals. Imaging was performed during 2013-2017, and all patients were reevaluated for the EDSS score in May 2018. Importantly, no adverse effects were observed during the follow-up period of patients.

\section{MRI and data analysis}

For the evaluation of MS pathology and for the acquisition of anatomic reference for the PET images, conventional MRI was performed with a 3-T Ingenuity TF PET/MR scanner (Philips). MRI of the healthy control group was performed with a Gyroscan Intera 1.5-T Nova Dual scanner for anatomic reference for the PET images (Philips). The following MRI sequences were used for image acquisition: axial $\mathrm{T} 2$, 3-dimensional (3D) fluid-attenuated inversion recovery, 3D $\mathrm{T} 1$, and 3D T1 with gadolinium enhancement.

For each patient, the $\mathrm{T} 1$ image at the first time point was coregistered in statistical parametric mapping (SPM8, version 8; Wellcome Trust Centre for Neuroimaging) to the sum image of realigned PET frames of the first session. All the other MRIs from the first session and the 1-year follow-up were then coregistered to the $\mathrm{T} 1 \mathrm{image}$ of the first session. For each time point, the MS lesions were identified using the Lesion Segmentation Tool (statistical-modelling.de/lst.html, a toolbox running in SPM8), ${ }^{11}$ as described previously. ${ }^{5}$ The resulting lesion mask images were used to fill the corresponding T1 image with the lesion-filling tool in the Lesion Segmentation Tool. The filled T1 was then used for segmenting gray matter (GM) and WM volumes with FreeSurfer 5.3 software (surfer.nmr.mgh.harvard.edu/). 
Table Demographic information and imaging parameters of the study cohort

\begin{tabular}{|c|c|c|c|c|c|c|c|c|}
\hline & & & \multicolumn{3}{|c|}{ Natalizumab $(n=10)$} & \multicolumn{2}{|c|}{ No treatment $(n=11)$} & $p$ Value \\
\hline \multicolumn{9}{|c|}{ Demographic information of the study patients } \\
\hline \multicolumn{3}{|c|}{ SPMS $(n=16,76 \%)$} & \multicolumn{2}{|c|}{$6(60 \%)$} & \multicolumn{3}{|c|}{$10(91 \%)$} & 0.097 \\
\hline \multicolumn{3}{|c|}{ RRMS (n = 5, 24\%) } & \multicolumn{2}{|c|}{$4(40 \%)$} & & \multicolumn{2}{|l|}{$1(9 \%)$} & \\
\hline \multicolumn{3}{|l|}{ Age, y } & \multicolumn{2}{|c|}{$49.15( \pm 9.33)$} & & \multicolumn{2}{|c|}{$47.88( \pm 10.23)$} & 0.700 \\
\hline \multicolumn{3}{|l|}{ Female } & \multicolumn{2}{|c|}{$6(60 \%)$} & & \multicolumn{2}{|l|}{$7(64 \%)$} & 0.864 \\
\hline \multicolumn{3}{|l|}{ Male } & \multicolumn{2}{|c|}{$4(40 \%)$} & & \multicolumn{2}{|l|}{$4(36 \%)$} & \\
\hline \multicolumn{3}{|c|}{ Years since SPMS diagnose } & \multicolumn{2}{|c|}{$3.58( \pm 1.82, \mathrm{n}=6)$} & & \multicolumn{2}{|c|}{$3.44( \pm 2.29, \mathrm{n}=10)$} & 0.830 \\
\hline \multicolumn{3}{|c|}{ No. of Gd+ lesions } & \multicolumn{2}{|l|}{0} & & \multicolumn{2}{|l|}{0} & \\
\hline \multicolumn{3}{|c|}{ Years since MS onset } & \multicolumn{2}{|c|}{$13.82( \pm 8.63)$} & & \multicolumn{2}{|l|}{$15.11( \pm 6.93)$} & 0.600 \\
\hline \multicolumn{3}{|c|}{ EDSS score (median and IQR) } & \multicolumn{2}{|c|}{$3.5(2.62-3.88)$} & & \multicolumn{2}{|c|}{$6.0(3.75-6.0)$} & $0.036^{\mathrm{a}}$ \\
\hline \multicolumn{3}{|c|}{ No. of relapses 1 year before } & \multicolumn{2}{|c|}{$0.70( \pm 0.82)$} & & \multicolumn{2}{|l|}{$0.27( \pm 0.47)$} & 0.220 \\
\hline & $\begin{array}{l}\text { Natalizumab } \\
\text { baseline }\end{array}$ & $\begin{array}{l}\text { Natalizumab } \\
\text { follow-up }\end{array}$ & $\begin{array}{l}\text { Natalizumab } \\
\text { change }^{\text {b }}\end{array}$ & $\begin{array}{l}\text { No } \\
\text { treatment } \\
\text { baseline }\end{array}$ & $\begin{array}{l}\text { No } \\
\text { treatment } \\
\text { follow-up }\end{array}$ & $\begin{array}{l}\text { No } \\
\text { treatment } \\
\text { change }^{\text {b }}\end{array}$ & $\begin{array}{l}\text { Baseline: no } \\
\text { treatment vs } \\
\text { natalizumab }\end{array}$ & $\begin{array}{l}\text { Follow-up: no } \\
\text { treatment vs } \\
\text { natalizumab }^{\text {b }}\end{array}$ \\
\hline \multicolumn{9}{|l|}{$\begin{array}{l}\text { Results related } \\
\text { to conventional } \\
\text { MRI parameters } \\
\text { and clinical } \\
\text { outcome } \\
\text { measures }\end{array}$} \\
\hline EDSS score & 3.55 & 3.80 & $0.037^{a}$ & 5.09 & 5.32 & 0.089 & $0.036^{a}$ & 0.051 \\
\hline $\begin{array}{l}\text { T2 lesion } \\
\quad \text { load }\left(\mathrm{cm}^{3}\right)\end{array}$ & 14.74 & 13.31 & 0.262 & 28.87 & 27.38 & 0.351 & $0.018^{a}$ & $0.018^{a}$ \\
\hline $\begin{array}{l}\text { T1 lesion } \\
\quad \text { load }\left(\mathrm{cm}^{3}\right)\end{array}$ & 13.86 & 12.35 & 0.103 & 26.81 & 25.40 & 0.197 & $0.022^{a}$ & $0.010^{a}$ \\
\hline $\begin{array}{l}\text { GM volume } \\
\left(\mathrm{cm}^{3}\right)\end{array}$ & 437.32 & 430.88 & $0.032^{a}$ & 433.09 & 425.05 & $0.023^{a}$ & 0.916 & 0.751 \\
\hline $\begin{array}{l}\text { NAWM } \\
\text { volume } \\
\left(\mathrm{cm}^{3}\right)\end{array}$ & 443.68 & 443.22 & 0.683 & 425.69 & 423.72 & 0.689 & 0.504 & 0.418 \\
\hline $\begin{array}{l}\text { Relapses } \\
\text { within } 1 \\
\text { year }\end{array}$ & 0.70 & 0.20 & 0.089 & 0.27 & 0.45 & 0.424 & 0.220 & 0.397 \\
\hline
\end{tabular}

\begin{tabular}{llll}
\hline \multicolumn{1}{l}{$\begin{array}{l}\text { Microglial activation measured as [11C]PK11195 distribution } \\
\text { volume ratio at baseline }\end{array}$} & Natalizumab $(\mathbf{n = 1 0})$ & No treatment $(\mathbf{n}=\mathbf{1 1})$ \\
\hline NAWM & 1.25 & 1.25 & 1.000 \\
\hline GMcortex & 1.25 & 1.22 & 0.477 \\
\hline Thalamus & 1.36 & 1.38 & 0.699 \\
\hline Putamen & 1.30 & 1.31 & 1.000 \\
\hline T1 & 1.19 & 1.19 & 0.751 \\
\hline T2 & 1.18 & 1.18 \\
\hline Lesion rim $\mathbf{3 - 6 ~} \mathbf{m m}$ & 1.24 & 1.23 & 0.916 \\
\hline
\end{tabular}

Abbreviations: DVR = distribution volume ratio; EDSS = Expanded Disability Status Scale; Gd+ = gadolinium enhancing positive; GM = gray matter; NAWM = normal-appearing white matter; RRMS = relapsing-remitting MS; SPMS = secondary progressive MS.

Values are the mean $( \pm$ SD where indicated) of the variables unless otherwise stated.

a Statistically significant group difference at a level of $p<0.05$.

${ }^{\mathrm{b}} p$ Value. 
The volumes of T2 lesion masks acquired with the Lesion Segmentation Tool were used for the T2 lesion load evaluation. In addition, for each patient, the Lesion Segmentation Tool masks at each time point were combined to a unified lesion region of interest (ROI). An average filled T1 image was also calculated from the filled $\mathrm{T} 1$ images of all MRI sessions, and it was used for ROI delineation for the cerebellum, striatum, thalamus, WM, and cortical GM with FreeSurfer. Furthermore, an NAWM ROI was created by removing the lesion ROI from the WM ROI. Perilesional 3-6 mm ROI with a distance of 3-6 $\mathrm{mm}$ to the lesion mask border was created by dilating the lesion mask image $3 \mathrm{~mm}$ and $6 \mathrm{~mm}$ and then removing the core from the resulting image. All ROIs were checked and manually corrected slice by slice with both T1hypointense and T2-hyperintense lesion mask images to accurately correspond to the MS lesions.

\section{$\left[{ }^{11} \mathrm{C}\right] \mathrm{PK} 11195$ radioligand production and PET}

The radiochemical synthesis of $\left[{ }^{11} \mathrm{C}\right] \mathrm{PK} 11195$ was performed as described previously. ${ }^{5}$ The mean injected dose was $475.5 \pm 53.1 \mathrm{MBq}$ (mean $\pm \mathrm{SD})$ for natalizumab-treated patients with $\mathrm{MS}, 467.0 \pm 73.1 \mathrm{MBq}$ for untreated patients with MS, and $478.6 \pm 17.7 \mathrm{MBq}$ for the healthy controls with no significant dose differences between the groups.

PET was performed with a brain-dedicated High-Resolution Research Tomograph scanner (Siemens/Control Technology Incorporated, Knoxville, TN) with an intrinsic spatial resolution of approximately $2.5 \mathrm{~mm} .{ }^{12}$ First, a 6-minute transmission scan for attenuation correction was obtained using a ${ }^{137} \mathrm{Cs}$ point source. Thereafter, 60-minute dynamic imaging was started simultaneously with IV bolus injection of the radioligand. Head movements were minimized using a thermoplastic mask.

\section{PET analysis}

PET images were reconstructed using 17 time frames as described previously. ${ }^{5}$ The dynamic data were then smoothed using a Gaussian 2.5-mm postreconstruction filter. ${ }^{5}$ Possible displacements between frames were corrected using mutual information realignment in SPM8. For each patient, the PET image from the subsequent session was coregistered to the PET image of the first session using the sum images of each session. Finally, all images were resliced to match an MR voxel size of $1 \mathrm{~mm}$.

Microglial activation was evaluated as specific binding of $\left[{ }^{11} \mathrm{C}\right]$ PK11195 using the distribution volume ratio (DVR). For the estimation of the $\left[{ }^{11} \mathrm{C}\right] \mathrm{PK} 11195 \mathrm{DVR}$, the timeactivity curve corresponding to a reference region devoid of specific TSPO binding was acquired for each PET session using a supervised cluster algorithm with 4 predefined kinetic tissue classes (SuperPK software). ${ }^{13}$ The reference tissueinput Logan method, with a 20- to 60-minute time interval, was applied to the regional time-activity curves using the supervised cluster algorithm gray reference input.

In addition, voxel-wise parametric binding potential $\left(\mathrm{BP}_{\mathrm{ND}}\right)$ maps were calculated using basis function implementation of
SRTM $^{14}$ with 250 basis functions. Lower and upper bounds for theta were set to $0.061 / \mathrm{min}$ and $0.81 / \mathrm{min}$. The resulting parametric maps were normalized to MNI space (Montreal Neurological Institute database) in SPM8, after which the difference $\mathrm{BP}_{\mathrm{ND}}$ images between PET scans ( 1 year-baseline) were calculated for statistical parametric mapping of differences between the 2 groups. The $\mathrm{BP}_{\mathrm{ND}}$ images were transformed to DVR $\left(\mathrm{DVR}=\mathrm{BP}_{\mathrm{ND}}+1\right)$ for illustration purposes.

\section{Statistical analysis}

Statistical analyses were performed using $\mathrm{R}$ (version 3.5.2). Variables are reported as median (interquartile range $[\mathrm{IQR}]$ ). Mainly nonparametric tests were used because of the low number of subjects in both groups. The analysis of differences in demographic variables in the 2 groups was conducted using the Wilcoxon rank-sum test; for the differences in proportions of patients with SPMS and females, a $\chi^{2}$ test was used. The differences in DVR values and MRI parameters in the 2 groups were compared using the Wilcoxon rank-sum test. The changes of DVR values and MRI parameters between followup and baseline were analyzed separately in both treatment groups using the Wilcoxon signed-rank test. All correlations are Spearman correlations, as the relationships between the variables could not be seen as linear. The partial correlations between the variables (EDSS change and DVR values) were adjusted for the time between the EDSS measurements as follows. The variables were regressed on the time difference, and the residuals of the model, i.e., the part in which the time difference impact has been removed, were used to calculate the partial correlations. A $p$ value less than 0.05 from a 2 -tailed test was considered statistically significant for all analyses.

\section{Standard protocol approvals, registrations, and patient consents}

The study was approved by the Ethics Committee of the Hospital District of Southwest Finland. All participants provided written informed consent according to the Declaration of Helsinki.

\section{Data availability statement}

The raw data used in preparation of the article will be shared in anonymized format by request of a qualified investigator.

\section{Results}

The demographic characteristics, conventional MRI data, and clinical outcome measures of the patients are shown in the table, top section. In total, 21 patients took part in the study, and $16(76 \%)$ of them had SPMS. Of the 10 natalizumabtreated patients, 2 were treatment naive, and the rest were switching from other therapies, which included fingolimod and interferon beta-1a. The median time since previous treatment was 2 months (IQR $1-3$ months). The second PET and MRI images were obtained 54.6 weeks (median, IQR 53.0-60.1 weeks) after the baseline imaging among natalizumab-treated patients and 54.0 weeks (median, IQR 
53.0-64.1 weeks) among the untreated patients. The reason for starting natalizumab was treatment failure with a previous drug, based on either clinical relapses or high or increasing MRI lesion burden, or initial aggressive disease in case of the treatment-naive patients.

In the untreated group, the median time since previous treatment was 16 months (IQR 4.5-27.5 months). None of the patients had gadolinium-enhancing lesions in either MRI scan. The untreated group had higher T1 and T2 lesion loads compared with the natalizumab-treated group (table, middle section). The natalizumab-treated group, which also included patients with RRMS, had a lower median EDSS score at baseline (table, top section). Compared with a group of age-matched healthy control persons $(\mathrm{n}=8$, historical data obtained and analyzed similarly to the methodology in this study), the patients with MS participating in this study had significantly more microglial activation in the NAWM $(p=0.026)$ and thalamus $(p=0.005)$ at baseline (figure 1A). In other ROIs, no significant differences were observed between the groups (data not shown). No significant differences were observed in the baseline DVRs between the natalizumab-treated and untreated groups in any brain area studied (table, bottom section).

Natalizumab treatment reduced microglial activation in the NAWM. This was demonstrated as a significantly smaller DVR of the TSPO radioligand binding after treatment vs before treatment ( 1.22 vs $1.25 ; p=0.014$, Wilcoxon, figure $1 B)$. The same was true for the 3- to 6-mm perilesional area ( 1.18 vs $1.24 ; p=0.014$, figure $1 \mathrm{~B})$. Similarly, there was a decrease in microglial activation following natalizumab treatment in focal inflammatory lesions (figure 1B).

Contrary to the natalizumab-treated patients, we observed an increase in microglial activation during 1-year follow-up of patients with MS with no treatment. Here, the DVR of the TSPO radioligand binding increased from 1.23 to 1.27 ( $p=$ 0.045 ) in the 3- to $6-\mathrm{mm}$ perilesional area, and in the NAWM, there was a trend toward the increase, from 1.25 to $1.28 ; p=0.068$ (figure 1B). No alteration was observed in microglial activation in the GM in either group (figure 1B). Differences in microglial activation in natalizumab-treated vs untreated patients were confirmed using an independent voxel-based whole brain analysis of parametric $\mathrm{BP}_{\mathrm{ND}}$ difference images (figure 2). Figure 3 demonstrates representative PET and MRIs before and after untreated follow-up of 1 year (A) and before and after natalizumab treatment (B), with surface plots visualizing the microglial activity around the chosen lesions.

Both patient groups were evaluated for development of clinical disability using the EDSS score at baseline and after 1 year. In both groups the median EDSS score was unaltered after 1 year (3.5 among natalizumab-treated cohort, figure $4 \mathrm{~A}$, and 6.0 among untreated cohort, figure 4B).
Furthermore, in the untreated group, the EDSS score was reevaluated after an average of 4 years (median 48.7 months, IQR 38.4-56.3 months) with a median value of 6.5. Higher baseline TSPO radioligand binding in the NAWM and in the 3-6 $\mathrm{mm}$ perilesional area was associated with a greater EDSS score increase during the follow-up $(p=0.013$ and $p=0.003$, respectively; figure $4, C$ and $D$ ). Spearman partial correlations, where the effect on the time between the measurements has been removed, confirmed these results $(p=0.013$ and $p=0.007$, respectively). Because some patients in the treated group terminated the natalizumab medication after the 1-year follow-up, no later evaluation of the EDSS score was performed in this group.

\section{Discussion}

The results from this longitudinal in vivo PET study of a total of 21 patients with MS demonstrate that microglial activation is reduced following 1 year treatment with natalizumab. Our study confirms reduction in microglial activation in focal MS lesions as shown before, ${ }^{15}$ but now indicates it also in areas relevant for MS disease progression such as the NAWM and the perimeter of chronic T1 lesions. It is expected that treatments leading to reduced microglial activation in these areas will help slow down the neurodegenerative process and disease progression in MS. ${ }^{8}$

Microglial activation in the MS brain has been evaluated in cross-sectional neuropathologic studies ${ }^{16-18}$ and in crosssectional PET imaging studies among patients with MS. $^{3-6,19-28}$ The results from these multiple studies are concordant and demonstrate increasing microglial activation in the NAWM and in the perilesional areas with advancing disease. Few longitudinal TSPO-PET studies have addressed therapeutic effects on microglia. ${ }^{15,29-31}$ They indicate that the present MS therapies are effective in reducing activation of the innate immune system within the CNS, particularly in association with lesions. We demonstrate now for the first time a reduction in microglial activation both in the NAWM and at the rim of chronic active lesions. This confirms that the diffuse smoldering inflammation associated with MS disease progression can be therapeutically targeted using efficient anti-inflammatory medication. Monoclonal antibodies, such as natalizumab, are large proteins and likely do not enter the CNS in any significant amount through an intact blood-brain barrier. ${ }^{32}$ Hence, we interpret that the positive study result is mostly due to efficient blocking of inflammatory cell entry from the periphery into the CNS rather than direct effect of natalizumab on the resident innate immune cell population within the CNS. In fact, it has been demonstrated earlier in a series of elegant animal experiments that CNS-entering autoreactive $\mathrm{T}$ cells induce microglial activation and enhance TSPO expression. ${ }^{33}$

Our study was performed as an investigator-initiated substudy to the ASCEND study. ASCEND (sponsored by Biogen 
A

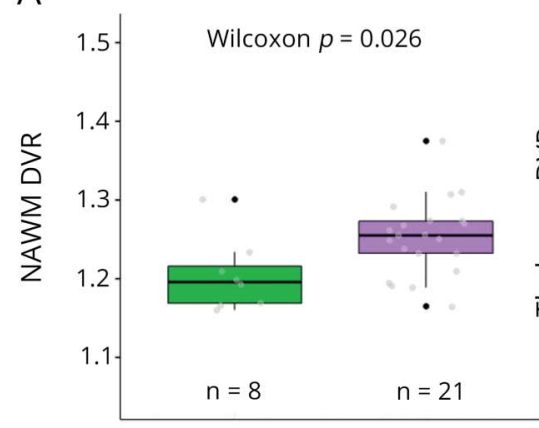

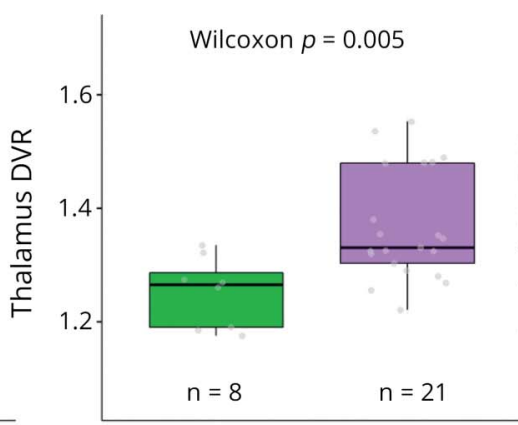

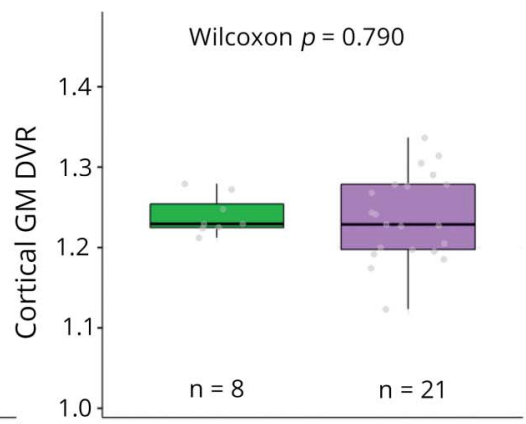

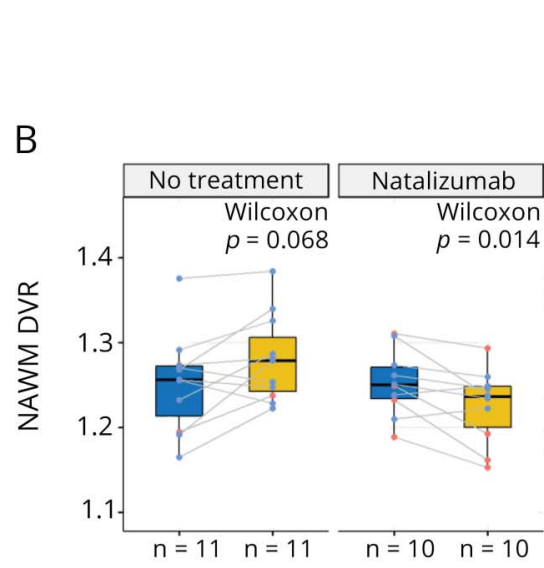
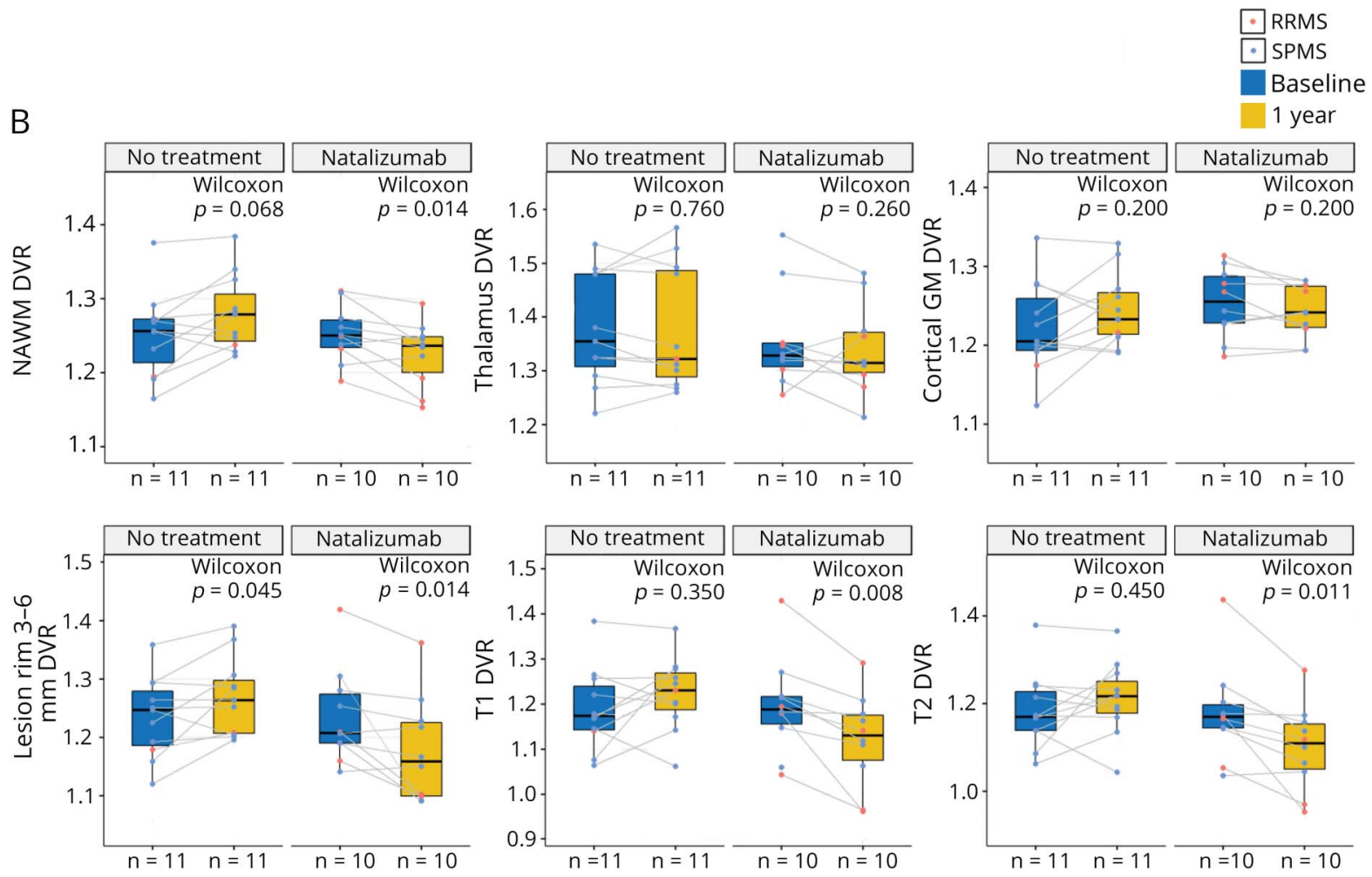

Evaluation of microglial activation in different brain regions of interest performed using TSPO-PET imaging and $\left[{ }^{11} \mathrm{C}\right]$ PK11195 radioligand. (A) Boxplots of $\left[{ }^{11} \mathrm{C}\right]$ PK11195 DVR values in the NAWM, thalamus, and cortical GM of patients with MS $(n=21)$ and healthy controls $(n=8)$ at baseline. Microglial activation was increased in the NAWM and thalamus in patients with MS compared with controls, but not in the cortical GM. (B) Boxplots of [ $\left.{ }^{11} \mathrm{C}\right]$ PK11195 DVR values in different brain areas of untreated $(n=11)$ and natalizumab-treated $(n=10)$ patients with MS at baseline and at 1-year time points. The differences in DVR values between time points were compared using the Wilcoxon signed-rank test. Asterisk denotes statistically significant group difference at a level of $p<0.05$. $\mathrm{DVR}=$ distribution volume ratio; GM = gray matter; NAWM = normal-appearing white matter; RRMS = relapsing-remitting MS; SPMS = secondary progressive MS; TSPO = translocator protein .

Idec) was a phase 3 double-blind placebo-controlled randomized controlled trial in SPMS. ${ }^{10}$ In this study, natalizumab treatment did not meet the primary efficacy end point of reducing sustained disability progression unrelated to relapses. This was measured by a multicomponent end point, which included the EDSS, Timed 25-Foot Walk, and 9-Hole Peg Test (9HPT). Natalizumab treatment did however reduce worsening of hand function of the patients in this study, as measured by the 9HPT. This, along with our findings of reduced microglial activation following natalizumab treatment, suggests that natalizumab treatment can be useful even in an advanced MS patient cohort, despite of the negative primary outcome in ASCEND. Problems of EDSS measurement as a clinical outcome in studies of progressive MS are well recognized, and the EDSS was slow to respond to treatment also in the present study. Because preserving upper limb function is highly desirable among patients, the 9HPT has been suggested as a primary outcome in some studies of progressive MS, with a final aim to maintain the usability of hands of patients. ${ }^{34,35}$ 
Figure 2 Demonstration of the natalizumab-induced reduction in $\left[{ }^{11} \mathrm{C}\right] \mathrm{PK} 11195$ binding compared with the change in the untreated group

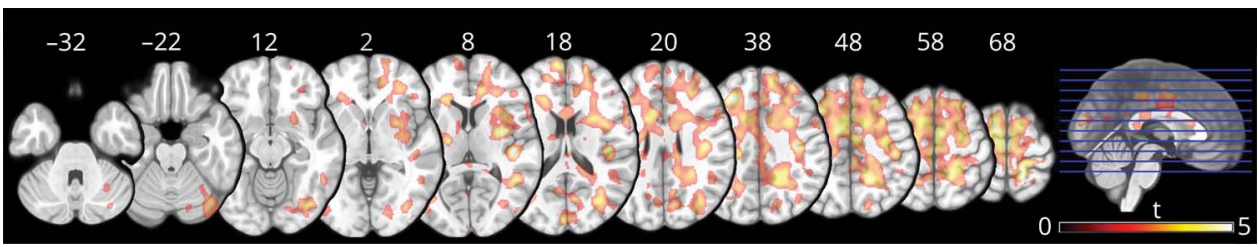

Statistical parametric mapping was used to demonstrate brain areas where radioligand binding is significantly different between natalizumabtreated and untreated patient cohorts. Two-sample $t$-test was performed with normalized parametric binding potential $\left(B P_{\mathrm{ND}}\right)$ difference images between PET scans (1 year-baseline) in MNI space (Montreal Neurological Institute database), where the images were smoothed with 3D Gaussian 8$\mathrm{mm}$ FWHM filter to ensure normality before the statistical analysis. Multiple comparisons were corrected using the family-wise error (FWE) rate, and the critical significance level to reject the null hypothesis was set to 0.05 .

Ours is the first study to evaluate longitudinally the natural evolution of MS disease pathology in terms of glial activation. We show that microglial activation increased during natural evolution of MS disease in the NAWM and perilesional areas during a period of 1 year. This was demonstrated in the control group of untreated patients with MS who mostly presented with secondary progressive disease type. Microglial activation is thus a dynamic process associated with MS disease evolution and can be measured using longitudinal in vivo TSPO-PET imaging. Of interest, higher degree of microglial activation in the NAWM and in the perilesional area in the baseline PET images of the untreated patients correlated with a greater increase in the EDSS score during follow-up of a median duration of 4 years. This observation supports the hypothesis that microglial activation plays an eminent role in contributing to clinical disability and suggests that the level of microglial activation could be used as a predictive imaging biomarker for MS disease progression. To identify those patients who are more likely to progress would be of significant value both for choosing treatments aiming to reduce disease progression for patients with MS in the clinic and for choosing suitable patients with MS for clinical trials of progressive MS.

The single previously published longitudinal TSPO-PET study evaluating the effect of natalizumab treatment detected a significant decrease in microglial activation in both enhancing and nonenhancing lesions. The investigators concluded that the NAWM had stable $\left[{ }^{11} \mathrm{C}\right]$ PK11195 uptake over 6 months and thereafter deemed the NAWM as an ideal reference tissue. The lack of treatment effect on the NAWM in the study by Kaunzner et al. ${ }^{15}$ may be due to the shorter treatment time compared with our study (6 months vs 12 months). Similarly, 6-month fingolimod treatment did not reduce the microglial activation within the NAWM. ${ }^{30}$ Because of the heterogeneous nature of the natalizumab-treated patient cohorts in these studies, it remains uncertain whether treatment of a pure SPMS patient population would lead to

Figure 3 Visual demonstration of the change in periplaque microglial activation in the MS brain
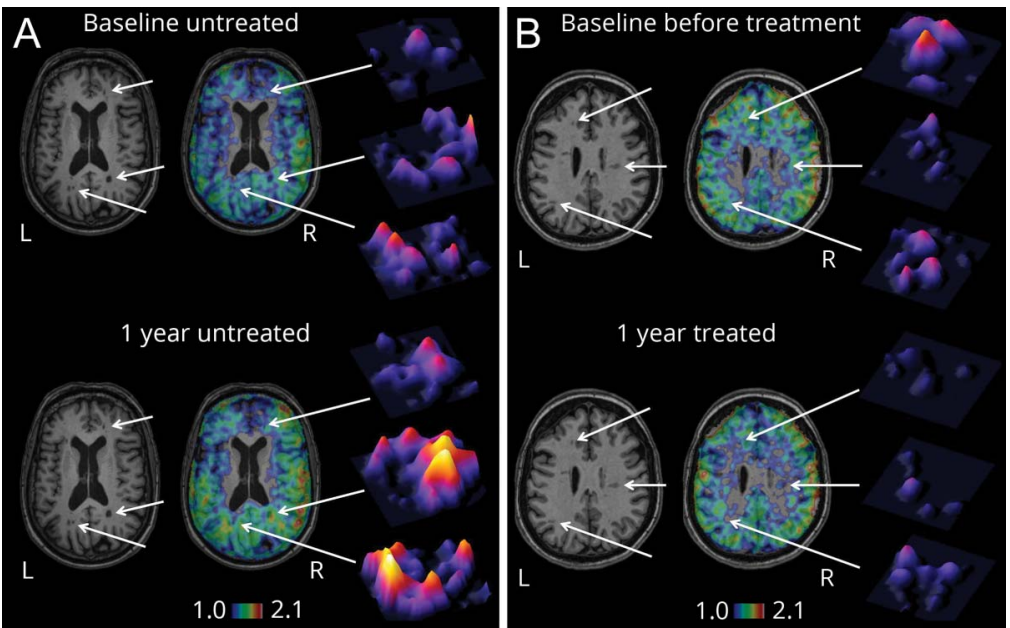

Demonstration of alteration in microglial activation in in dividual untreated SPMS and natalizumab-treated RRMS patients. (A) Axial view of 3DT1 MRIs and respective DVR images at baseline (top row) and after 1 year (bottom row) in an untreated patient with MS (a 53-year-old woman with 29 years of MS and 2 years of SPMS and EDSS score of 6.0 at baseline and 6.5 at follow-up). The radioligand binding increases at the edge of chronic black holes during the follow-up (white arrows). This can also be visualized using surface plots of the chosen lesions (on the right). (B) Axial view of 3DT1 MRIs and respective DVR images at baseline (top row) and after 1 year (bottom row) of natalizumab treatment (a 46-year-old woman with 7.6 years of RRMS and EDSS score of 2). The radioligand binding decreases at the edge of chronic black holes during treatment (white arrows). The surface plots on the right visualize the decreased microglial activation around the chosen lesions. DVR = distribution volume ratio; EDSS = Expanded Disability Status Scale; RRMS = relapsing-remitting MS; SPMS = secondary progressive MS. 

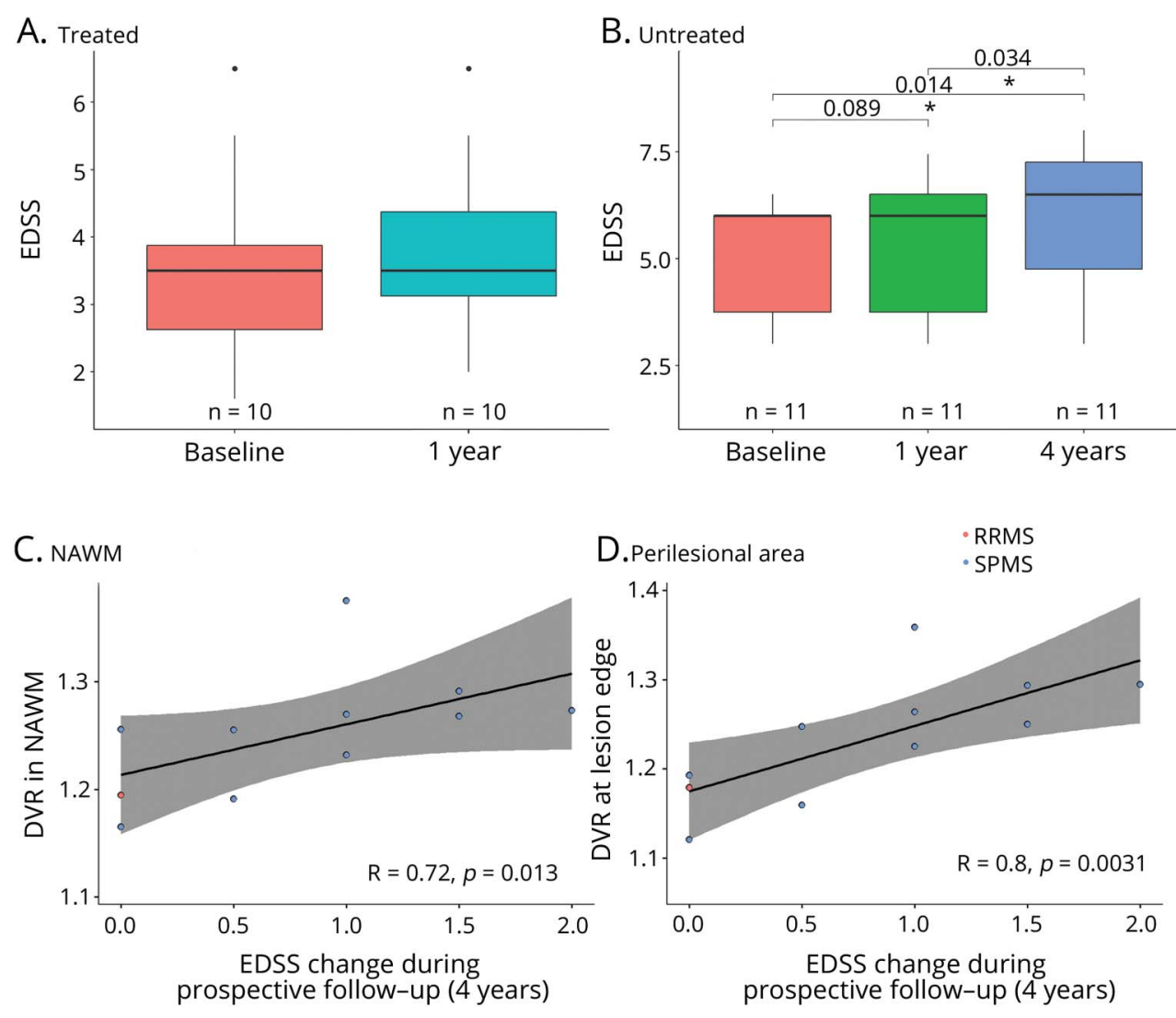

(A) Boxplots of EDSS values at baseline and at 1 year follow-up in the natalizumab-treated group $(\mathrm{n}=$ 10). The median EDSS score was not altered during the year of natalizumab treatment. The median EDSS score was 3.5 (IQR 2.62-3.88) at baseline and 3.5 (IQR 3.12-4.38) after 1 year. When EDSS values between the time points were compared using the Wilcoxon signed-rank test, a slight difference was observed between the values ( $p$ $=0.037$ ). (B) Boxplots of EDSS values at baseline, 1 year, and at an average of 4-year follow-up among untreated patients $(n=11)$. The median EDSS score was not altered during the first follow-up year. The median EDSS score was 6.0 (IQR $3.75-6.0$ ) at baseline and 6.0 (IQR 3.75-6.5) after 1 year. By 4 years, the median EDSS score was increased to 6.5 (IQR 4.75-7.25). The differences in EDSS values between the time points were compared using the Wilcoxon signed-rank test. After adjusting the $p$ values for multiple comparisons (Holm method), a statistically significant difference was observed only between the baseline and 4 years $(p=0.041)$. (C and D) Higher baseline $\left[{ }^{11} \mathrm{C}\right]$ PK11195 DVR values in the NAWM and 3-6 mm perilesional area associated with a greater EDSS score increase during the 4 -year follow-up $(n=11)$. The correlation analysis was performed using Spearman correlation. Asterisk denotes statistically significant group difference at a level of $p<$ 0.05 . DVR = distribution volume ratio; EDSS = Expanded Disability Status Scale; IQR = interquartile range; NAWM = normal-appearing white matter; RRMS = relapsing-remitting MS; SPMS = secondary progressive MS. similar reduction in microglial activation. This will need to be confirmed in a separate study. No alteration was observed in microglial activation in the GM in the present study.

$\left[{ }^{11} \mathrm{C}\right] \mathrm{PK} 11195$ is the first and most widely used TSPObinding PET ligand in imaging of neuroinflammation. ${ }^{36} \mathrm{We}$ chose to use the $\left[{ }^{11} \mathrm{C}\right] \mathrm{PK} 11195$ in this study because the analysis methods for quantification of $\left[{ }^{11} \mathrm{C}\right] \mathrm{PK} 11195$ binding have been carefully developed, and longitudinal image acquisition can be performed with ease without arterial cannulation and with good reproducibility. ${ }^{13,37}$ New second- and thirdgeneration TSPO ligands with better binding characteristics have been developed and tested also in imaging of MS.,22-28 These, however, show heterogeneous binding to TSPO due to genetic polymorphism (rs6971), which complicates interpretation of the results. Moreover, the best quantification methods for these ligands are still being sought. ${ }^{38}$ TSPO expression in the brain is not specific for activated microglia, but also some astrocytes, macrophages, and endothelial cells express the molecule. The specificity of TSPO binding regarding M1-like and M2-like microglia has been unclear, but recent evidence from in vitro and animal studies suggests that the increased expression of TSPO in neuroinflammation predominates in proinflammatory M1-like microglia. ${ }^{39}$

Natalizumab, by blocking the entry of autoreactive lymphocytes and monocytes into the CNS, is one of the most effective disease-modifying treatments for RRMS. ${ }^{40}$ Our results demonstrate that natalizumab treatment leads to reduced activation of microglia and macrophages behind an intact blood-brain barrier in brain areas relevant for disease progression. The study thus supports the usability of TSPO-PET imaging as a surrogate outcome measure in studies of progressive MS and opens new vistas for designing future therapeutic studies in progressive MS.

\section{Study funding}

This work was supported by Biogen Idec, Finnish Academy, Sigrid Juselius Foundation, The Finnish MS Foundation, The Finnish Medical Foundation, The State Research Funding, and the European Union's Seventh Framework Programme (FP7/2007-2013) under grant agreement no. HEALTH-F22011-278850 (INMiND). 


\section{Disclosure}

M. Sucksdorff, J. Tuisku, M. Matilainen, A. Vuorimaa, S. Smith, J, Keitilä, J. Rokka, R. Parkkola, M. Nylund, and J. Rinne report no disclosures. E. Rissanen has received speaker honoraria from Teva, Biogen, and Roche, consultation fee from Merck, and personal research grants from Turku University Hospital and the Finnish MS Foundation. L. Airas: compensation for consulting-Merck and Roche; institutional support for research-Sanofi Genzyme and Biogen Idec. Go to Neurology.org/NN for full disclosures.

\section{Publication history}

Received by Neurology: Neuroimmunology \& Neuroinflammation December 19, 2018. Accepted in final form April 2, 2019.

Appendix Authors

\begin{tabular}{|c|c|c|c|}
\hline Name & Location & Role & Contribution \\
\hline $\begin{array}{l}\text { Marcus } \\
\text { Sucksdorff, } \\
\text { MD }\end{array}$ & $\begin{array}{l}\text { Turku PET Centre, } \\
\text { Turku University } \\
\text { Hospital and } \\
\text { University of } \\
\text { Turku, Turku, } \\
\text { Finland }\end{array}$ & $\begin{array}{l}\text { Corresponding } \\
\text { author and } \\
\text { investigator }\end{array}$ & $\begin{array}{l}\text { Study concept, } \\
\text { data collection, } \\
\text { manuscript } \\
\text { drafting, and } \\
\text { critical revision of } \\
\text { the manuscript }\end{array}$ \\
\hline $\begin{array}{l}\text { Jouni } \\
\text { Tuisku, MSc }\end{array}$ & $\begin{array}{l}\text { Turku PET } \\
\text { Centre, Turku } \\
\text { University } \\
\text { Hospital and } \\
\text { University of } \\
\text { Turku, Turku, } \\
\text { Finland }\end{array}$ & $\begin{array}{l}\text { Statistician and } \\
\text { image modeler }\end{array}$ & $\begin{array}{l}\text { Data collection } \\
\text { and analysis and } \\
\text { interpretation of } \\
\text { data }\end{array}$ \\
\hline $\begin{array}{l}\text { Markus } \\
\text { Matilainen, } \\
\text { PhD }\end{array}$ & $\begin{array}{l}\text { Turku PET } \\
\text { Centre, Turku } \\
\text { University } \\
\text { Hospital and } \\
\text { University of } \\
\text { Turku, Turku, } \\
\text { Finland }\end{array}$ & Statistician & $\begin{array}{l}\text { Data collection, } \\
\text { analysis and } \\
\text { interpretation of } \\
\text { data, and critical } \\
\text { revision of the } \\
\text { manuscript }\end{array}$ \\
\hline $\begin{array}{l}\text { Anna } \\
\text { Vuorimaa, } \\
\text { BM }\end{array}$ & $\begin{array}{l}\text { Turku PET } \\
\text { Centre, Turku } \\
\text { University } \\
\text { Hospital and } \\
\text { University of } \\
\text { Turku, Turku, } \\
\text { Finland }\end{array}$ & Investigator & $\begin{array}{l}\text { Data collection } \\
\text { and analysis of } \\
\text { data }\end{array}$ \\
\hline $\begin{array}{l}\text { Sarah } \\
\text { Smith, BSc }\end{array}$ & $\begin{array}{l}\text { Turku PET } \\
\text { Centre, Turku } \\
\text { University } \\
\text { Hospital and } \\
\text { University of } \\
\text { Turku, Turku, } \\
\text { Finland }\end{array}$ & Investigator & $\begin{array}{l}\text { Data collection, } \\
\text { analysis of data }\end{array}$ \\
\hline $\begin{array}{l}\text { Joonas } \\
\text { Keitilä, BM }\end{array}$ & $\begin{array}{l}\text { Turku PET Centre, } \\
\text { Turku University } \\
\text { Hospital and } \\
\text { University of } \\
\text { Turku, Turku, } \\
\text { Finland }\end{array}$ & Investigator & $\begin{array}{l}\text { Data collection } \\
\text { and analysis of } \\
\text { data }\end{array}$ \\
\hline $\begin{array}{l}\text { Johanna } \\
\text { Rokka, MSc, } \\
\text { PhD }\end{array}$ & $\begin{array}{l}\text { Turku PET } \\
\text { Centre, Turku } \\
\text { University } \\
\text { Hospital and } \\
\text { University of } \\
\text { Turku, Turku, } \\
\text { Finland }\end{array}$ & Investigator & Data collection \\
\hline
\end{tabular}

Appendix (continued)

\begin{tabular}{|c|c|c|c|}
\hline Name & Location & Role & Contribution \\
\hline $\begin{array}{l}\text { Riitta } \\
\text { Parkkola, } \\
\text { MD, PhD }\end{array}$ & $\begin{array}{l}\text { Department of } \\
\text { Radiology, } \\
\text { University } \\
\text { Hospital and } \\
\text { University of } \\
\text { Turku, Turku, } \\
\text { Finland }\end{array}$ & Investigator & $\begin{array}{l}\text { Data collection } \\
\text { and analysis of } \\
\text { data }\end{array}$ \\
\hline $\begin{array}{l}\text { Marjo } \\
\text { Nylund, } \\
\text { MSc }\end{array}$ & $\begin{array}{l}\text { Turku PET } \\
\text { Centre, Turku } \\
\text { University } \\
\text { Hospital and } \\
\text { University of } \\
\text { Turku, Turku, } \\
\text { Finland }\end{array}$ & Investigator & $\begin{array}{l}\text { Data collection } \\
\text { and critical } \\
\text { revision of the } \\
\text { manuscript }\end{array}$ \\
\hline $\begin{array}{l}\text { Juha Rinne, } \\
\text { MD, PhD }\end{array}$ & $\begin{array}{l}\text { Turku PET } \\
\text { Centre, Turku } \\
\text { University } \\
\text { Hospital and } \\
\text { University of } \\
\text { Turku, Turku, } \\
\text { Finland }\end{array}$ & Investigator & $\begin{array}{l}\text { Study concept } \\
\text { and } \\
\text { interpretation of } \\
\text { results }\end{array}$ \\
\hline $\begin{array}{l}\text { Eero } \\
\text { Rissanen, } \\
\text { MD, PhD }\end{array}$ & $\begin{array}{l}\text { Turku PET } \\
\text { Centre, Turku } \\
\text { University } \\
\text { Hospital and } \\
\text { University of } \\
\text { Turku, Turku, } \\
\text { Finland }\end{array}$ & Investigator & $\begin{array}{l}\text { Study concept, } \\
\text { acquisition and } \\
\text { interpretation of } \\
\text { data, and critical } \\
\text { revision of the } \\
\text { manuscript }\end{array}$ \\
\hline $\begin{array}{l}\text { Laura Airas, } \\
\text { MD, PhD }\end{array}$ & $\begin{array}{l}\text { Turku PET } \\
\text { Centre, Turku } \\
\text { University } \\
\text { Hospital and } \\
\text { University of } \\
\text { Turku, Turku, } \\
\text { Finland }\end{array}$ & $\mathrm{PI}$ & $\begin{array}{l}\text { Study concept } \\
\text { and design, } \\
\text { interpretation of } \\
\text { results, } \\
\text { manuscript } \\
\text { drafting, and } \\
\text { critical revision of } \\
\text { the manuscript }\end{array}$ \\
\hline
\end{tabular}

\section{References}

1. Frischer JM, Weigand SD, Guo Y, et al. Clinical and pathological insights into the dynamic nature of the white matter multiple sclerosis plaque. Ann Neurol 2015;78: $710-721$.

2. Herranz E, Giannì C, Louapre C, et al. Neuroinflammatory component of gray matter pathology in multiple sclerosis. Ann Neurol 2016;80:776-790.

3. Debruyne JC, Versijpt J, Van Laere KJ, et al. PET visualization of microglia in multiple sclerosis patients using [11C]PK11195. Eur J Neurol 2003;10:257-264.

4. Versijpt J, Debruyne JC, Van Laere KJ, et al. Microglial imaging with positron emission tomography and atrophy measurements with magnetic resonance imaging in multiple sclerosis: a correlative study. Mult Scler 2005;11:127-134.

5. Rissanen E, Tuisku J, Vahlberg T, et al. Microglial activation, white matter tract damage, and disability in MS. Neurol Neuroimmunol Neuroinflamm 2018;5:e443. doi: 10.1212/NXI.0000000000000443.

6. Rissanen E, Tuisku J, Rokka J, et al. In vivo detection of diffuse inflammation in secondary progressive multiple sclerosis using PET imaging and the radioligand ${ }^{11} \mathrm{C}$ PK11195. J Nucl Med 2014;55:939-944.

7. Mayo L, Quintana FJ, Weiner HL. The innate immune system in demyelinating disease. Immunol Rev 2012;248:170-187.

8. Gillen KM, Mubarak M, Nguyen TD, Pitt D. Significance and in vivo detection of IronLaden microglia in white matter multiple sclerosis lesions. Front Immunol 2018;9:255

9. Correale J. The role of microglial activation in disease progression. Mult Scler 2014; 20:1288-1295.

10. Kapoor R, Ho PR, Campbell N, et al. Effect of natalizumab on disease progression in secondary progressive multiple sclerosis (ASCEND): a phase 3, randomised, doubleblind, placebo-controlled trial with an open-label extension. Lancet Neurol 2018;17: $405-415$.

11. Schmidt P, Gaser C, Arsic M, et al. An automated tool for detection of FLAIRhyperintense white-matter lesions in multiple sclerosis. Neuroimage 2012;59: 3774-3783.

12. de Jong HW, van Velden FH, Kloet RW, Buijs FL, Boellaard R, Lammertsma AA. Performance evaluation of the ECAT HRRT: an LSO-LYSO double layer high resolution, high sensitivity scanner. Phys Med Biol 2007;52:1505-1526. 
13. Turkheimer FE, Edison $\mathrm{P}$, Pavese N, et al. Reference and target region modeling of [11C]-(R)-PK11195 brain studies. J Nucl Med 2007;48:158-167.

14. Gunn RN, Lammertsma AA, Hume SP, Cunningham VJ. Parametric imaging of ligand-receptor binding in PET using a simplified reference region model. Neuroimage 1997;6:279-287.

15. Kaunzner UW, Kang Y, Monohan E, et al. Reduction of PK11195 uptake observed in multiple sclerosis lesions after natalizumab initiation. Mult Scler Relat Disord 2017; 15:27-33.

16. Frischer JM, Bramow S, Dal-Bianco A, et al. The relation between inflammation and neurodegeneration in multiple sclerosis brains. Brain 2009;132:1175-1189.

17. Lassmann H, van Horssen J, Mahad D. Progressive multiple sclerosis: pathology and pathogenesis. Nat Rev Neurol 2012;8:647-656.

18. Moll NM, Rietsch AM, Thomas S, et al. Multiple sclerosis normal-appearing white matter: pathology-imaging correlations. Ann Neurol 2011;70:764-773.

19. Banati RB, Newcombe J, Gunn RN, et al. The peripheral benzodiazepine binding site in the brain in multiple sclerosis: quantitative in vivo imaging of microglia as a measure of disease activity. Brain 2000;123(pt 11):2321-2337.

20. Politis M, Giannetti P, Su P, et al. Increased PK11195 PET binding in the cortex of patients with MS correlates with disability. Neurology 2012;79:523-530.

21. Giannetti P, Politis M, Su P, et al. Microglia activation in multiple sclerosis black holes predicts outcome in progressive patients: an in vivo [(11)C](R)-PK11195-PET pilot study. Neurobiol Dis 2014;65:203-210.

22. Datta G, Colasanti A, Kalk N, et al. 11C-PBR28 and 18F-PBR111 detect white matter inflammatory heterogeneity in multiple sclerosis. J Nucl Med 2017;58:1477-1482.

23. Vas A, Shchukin Y, Karrenbauer VD, et al. Functional neuroimaging in multiple sclerosis with radiolabelled glia markers: preliminary comparative PET studies with [11C]vinpocetine and [11C]PK11195 in patients. J Neurol Sci 2008;264:9-17.

24. Oh U, Fujita M, Ikonomidou VN, et al. Translocator protein PET imaging for glial activation in multiple sclerosis. J Neuroimmune Pharmacol 2011;6:354-361.

25. Park E, Gallezot JD, Delgadillo A, et al. ((11)C-PBR28 imaging in multiple sclerosis patients and healthy controls: test-retest reproducibility and focal visualization of active white matter areas. Eur J Nucl Med Mol Imaging 2015;42:1081-1092.

26. Vomacka L, Albert NL, Lindner S, et al. TSPO imaging using the novel PET ligand [18F]GE-180: quantification approaches in patients with multiple sclerosis. EJNMMI Res $2017 ; 7: 89$.

27. Takano A, Piehl F, Hillert J, et al. In vivo TSPO imaging in patients with multiple sclerosis: a brain PET study with [18F]FEDAA1106. EJNMMI Res 2013;3:30.
28. Colasanti A, Guo Q, Muhlert N, et al. In vivo assessment of brain white matter inflammation in multiple sclerosis with (18)F-PBR111 PET. J Nucl Med 2014;55:1112-1118.

29. Ratchford JN, Endres CJ, Hammoud DA, et al. Decreased microglial activation in MS patients treated with glatiramer acetate. J Neurol 2012;259:1199-1205.

30. Sucksdorff M, Rissanen E, Tuisku J, et al. Evaluation of the effect of fingolimod treatment on microglial activation using serial PET imaging in multiple sclerosis. J Nucl Med 2017;58:1646-1651

31. Bunai $\mathrm{T}$, Terada $\mathrm{T}$, Kono $\mathrm{S}$, et al. Neuroinflammation following disease modifying therapy in multiple sclerosis: a pilot positron emission tomography study. J Neurol Sci 2018;385:30-33.

32. Hagens MH, Killestein J, Yaqub MM, et al. Cerebral rituximab uptake in multiple sclerosis: a (89)Zr-immunoPET pilot study. Mult Scler 2018;24:543-545.

33. Grebing M, Nielsen HH, Fenger CD, et al. Myelin-specific T cells induce interleukinlbeta expression in lesion-reactive microglial-like cells in zones of axonal degeneration. Glia 2016;64:407-424.

34. Giovannoni G, Cutter G, Sormani MP, et al. Is multiple sclerosis a length-dependent central axonopathy? The case for therapeutic lag and the asynchronous progressive MS hypotheses. Mult Scler Relat Disord 2017;12:70-78.

35. Giovannoni G, Airas L, Bove R, et al. Ocrelizumab treatment effect on upper limb function in PPMS patients with disability: subgroup results of the ORATORIO study to inform the ORATORIO-HAND study. Neurology 2019;92 (15 Suppl):P3.2-091. Available at: https://n.neurology.org/content/92/15 Supplement/P3.2-091.

36. Airas L, Rissanen E, Rinne JO. Imaging neuroinflammation in multiple sclerosis using TSPO-PET. Clin Transl Imaging 2015;3:461-473.

37. Kang Y, He B, Schlyer D, Vallabhajosula S, Mozley P. Reproducibility of test-retest with 11C -PK11195 using different input function approaches. J Nucl Med 2015;56:152.

38. Fujita M, Kobayashi M, Ikawa M, et al. Comparison of four (11)C-labeled PET ligands to quantify translocator protein $18 \mathrm{kDa}$ (TSPO) in human brain: (R)PK11195, PBR28, DPA-713, and ER176-based on recent publications that measured specific-to-non-displaceable ratios. EJNMMI Res 2017;7:84.

39. Beckers L, Ory D, Geric I, et al. Increased expression of translocator protein (TSPO) marks pro-inflammatory microglia but does not predict neurodegeneration. Mol Imaging Biol 2018;20:94-102.

40. Rae-Grant A, Day GS, Marrie RA, et al. Comprehensive systematic review summary: disease-modifying therapies for adults with multiple sclerosis: report of the guideline development, dissemination, and implementation subcommittee of the American Academy of neurology. Neurology 2018;90:789-800. 


\title{
Neurology \\ Neuroimmunology \& Neuroinflammation
}

\author{
Natalizumab treatment reduces microglial activation in the white matter of the MS \\ brain \\ Marcus Sucksdorff, Jouni Tuisku, Markus Matilainen, et al. \\ Neurol Neuroimmunol Neuroinflamm 2019;6; \\ DOI 10.1212/NXI.0000000000000574
}

This information is current as of June 7, 2019

Updated Information \&

Services

References

Citations

Subspecialty Collections

Permissions \& Licensing

Reprints including high resolution figures, can be found at:

http://nn.neurology.org/content/6/4/e574.full.html

This article cites 40 articles, 5 of which you can access for free at: http://nn.neurology.org/content/6/4/e574.full.html\#\#ref-list-1

This article has been cited by 2 HighWire-hosted articles: http://nn.neurology.org/content/6/4/e574.full.html\#\#otherarticles

This article, along with others on similar topics, appears in the following collection(s):

Multiple sclerosis

http://nn.neurology.org//cgi/collection/multiple_sclerosis

PET

http://nn.neurology.org//cgi/collection/pet

Information about reproducing this article in parts (figures,tables) or in its entirety can be found online at:

http://nn.neurology.org/misc/about.xhtml\#permissions

Information about ordering reprints can be found online:

http://nn.neurology.org/misc/addir.xhtml\#reprintsus

Neurol Neuroimmunol Neuroinflamm is an official journal of the American Academy of Neurology.

Published since April 2014, it is an open-access, online-only, continuous publication journal. Copyright

Copyright (C) 2019 The Author(s). Published by Wolters Kluwer Health, Inc. on behalf of the American

Academy of Neurology.. All rights reserved. Online ISSN: 2332-7812.

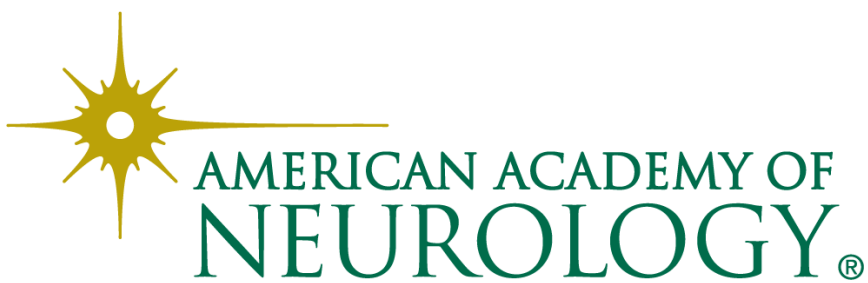

